cartography bulletin board

We are fortunate in this issue of $C P$ to have three individual submissions for the cartography bulletin board. The first is a summary of cartographic activities that took place at the 1994 Association of American Geographers Meeting in San Francisco in April. The second piece is a description of the activities of the Cartographic Research Laboratory at the University of Alabama. This is part of our ongoing series designed to feature university cartography laboratories and discuss their functions, equipment, and structure. The last item reports the results of a survey conducted on university cartography laboratories. Information from this survey was presented at the 1993 NACIS Annual Meeting and is a useful summary of cartographic laboratory activities and changes.

\section{Cartography at the 1994 Association of American Geographers Meeting}

by Jim Anderson, Director

Florida Resources \& Environmental Analysis Center

Florida State University

At the recently concluded annual meeting of the Association of American Geographers held in San Francisco, cartographers were well represented with twenty sessions, many of which were sponsored by the Cartography Specialty Group. Four workshops were also conducted: Mapping on the Macintosh Computer, An Introduction to GPS and Its Integration with GIS, Map Design and Production with COREL DRAW, and Mapping and Image Analysis Using Microcom- puters. NACIS members were well represented as participants. Of special interest to university cartography lab directors were sessions on multimedia, electronic atlases, teaching cartography, and $\mathrm{lab}$ and equipment grants. Other sessions dealt with cognitive cartography, TIGER, and state atlas funding.

Multimedia applications for cartography are emerging as major research interests as well as providing a source of funding for cartography labs. Multimedia, with the ability to link animation, video, sound, graphics, text, and photographs interactively, provides the cartographer with unique opportunities, but also many challenges. Two sessions dealing with multimedia cartography were held. One dealt with the development of electronic atlases. Examples of completed and ongoing projects were presented which gave an indication of the flexibility and design options that are available to the cartographer when developing a multimedia project. The other session titled "Multimedia Cartography" presented papers on four multimedia projects which have maps as one of their primary components. Considerations in animating maps were discussed and illustrated. Also, the issues of scanning methods and resolution, storage and image compression, cross platform development, database design, and delivery systems were presented. In the next issue of Cartographic Perspectives, multimedia activities at several cartography labs will be highlighted as well as reviews of several multimedia authoring software packages.

An interesting session on teaching cartography presented the viewpoints of several cartography instructors and included course outlines for their introductory cartography courses. Current teaching methodologies ranged from conventional pen and ink to total use of computers for cartography exercises. A discussion on the usefulness of teaching manual techniques evolved from the presentations. While no consensus was reached on this issue, there was general agreement that the teaching of map design and data representation techniques needed to remain an integral part of the curriculum. Two sessions dealt with the issue of equipping laboratories with computer equipment. Several speakers discussed their successful applications to the National Science Foundation's Instrumentation and Laboratory Improvement Program (ILI). The second session dealt with proposal writing for the ILI program. Next year's AAG meeting will be held in Chicago. I would encourage NACIS members to participate and work with the Cartography Specialty Group in organizing sessions or submitting papers. $]$

\section{The Cartographic Research Laboratory at the University of Alabama}

\section{by Craig Remington, Director Cartographic Research Laboratory University of Alabama}

The Cartographic Research Laboratory at the University of Alabama is part of the Geography Department and plays an integral role in the Department's teaching and research missions. Our Lab currently employs three student assistants who work under my supervision. Most of our projects, and therefore income, come from outside the Department. Our services are provided to the Department without charge. 